\title{
Introduction
}

\section{Ingenious Minds: British Women as Facilitators of Scientific Knowledge Exchange, 1810-1900}

\author{
Alison E. Martin
}

"In every science, in every branch of knowledge, more than ninety-nine hundredths of what is this day known have been discovered by male understandings," wrote the Irish chemist Richard Chenevix in his two-volume Essay upon National Character published in 1832 (II: 316). A work that sought to demonstrate in two weighty volumes how England had become the only truly civilised nation in Europe, it examined the processes by which "domestic and foreign prosperity, pride, virtue, wisdom, liberty" had come to be united in this country so successfully (I: 270). Yet the role that women might play in fostering such "wisdom" was - like his sweeping statement on their contribution to science - reduced to generalities. "The difference between male and female intellect is greater in searching after causes, in creating new knowledge, [...] it is less in appreciating individual facts, qualities, and relations," he added, thereby sustaining the nineteenth-century stereotype of women as good observers of detail, but not as the great minds that make inspired connections (II: 31617). It was more in the arts and manufactures that women could productively contribute: "they can lend their dexterous hands and their ingenious minds; and thus become more and more the companions of man, and the necessary partners of his toils and pleasures" (II: 333). Yet by the early 1830s, when Chenevix's Essay appeared, women had already demonstrated their active involvement in a range of rapidly evolving scientific disciplines. Thus while Chenevix relegated British women to the "empire of the drawing-room" where they might turn their "ingenious minds" to acting as useful helpmeets to their husbands, the reality already looked rather different (II: 321).

As the papers in this special themed issue demonstrate, women were beginning to acquire distinction as scientific travellers, collectors and specimen preservers, while also working as illustrators, authors, editors and translators of scientific literature. This collection of articles has developed from an international workshop held at the University of Reading in 2013 and the title "Ingenious Minds: British Women as Facilitators of Scientific Knowledge Exchange, 1810-1900" illustrates the project's overall themes. We are interested in the role that women played as often less "visible" mediators, co-ordinators and assistants in the construction or transmission of scientific knowledge in the nineteenth century, a period in which women's involvement in the sciences underwent profound changes. The women on whom we focus could be deemed "ingenious" not only for their strong intellectual capabilities, but also for their inventiveness in jumping the hurdles that limited them from achieving their goals and for their talented diplomacy in renegotiating the possibilities that their otherwise rather peripheral position offered them. Our collection therefore moves beyond the notion of scientifically-minded women as "victims" of a patriarchal society. Certainly, women were largely excluded from science by men in that they were physically kept out of scientific clubs, societies or educational institutions and, of course, professional posts. But what this collection explores is how women gradually removed or 
circumvented such barriers, using, as Londa Schiebinger has termed it, "their culturally defined difference as a platform for critique" (307).

This collection therefore considers how women employed a range of narrative possibilities in their writing, translating and editing work not only to present new scientific findings to a British reading public but also to demonstrate their own proficiency in science. As Charlotte Sleigh reminds us, science "cannot be conducted without language, and language is not a neutral tool" (6). Since it actively shapes not only what is conveyed, but how, the style adopted by scientific writers and the general form of their work is significant in indicating how they conceive of the content of the work, its position within the tradition of scientific textual production and the type of audience they seek to instruct and entertain. While we are interested in the textual form that characterised a piece of scientific writing, our concern is also to understand how these texts were brought to press and enjoyed by a range of different readers. As material artefacts, the books we discuss here, whether privately published with an extremely small print-run or destined for much larger, highly competitive, national markets, all entered into what Robert Darnton has termed a "communications circuit" (495). The ways that a book is written, edited, published, illustrated, translated, advertised, bought, sold and reviewed, have the potential all to be deeply significant in enabling us to understand how scientific knowledge is produced and consumed. As James A. Secord has recently argued, science was "central to defining the meaning of print" in the nineteenth century, precisely because these products emerging from publishing houses were "tangible evidence of spiritual and material progress," even if we still know surprisingly little about how these presses were used to "announce novelties and more generally to create images of science and invention" ("Science, Technology and Mathematics" 443).

Our collection also reflects an ongoing concern with the "woman question" in science and the "science question" in women's writing that was also the subject of two London conferences in 2014: Claire Jones and Sue Hawkins' "Revealing Lives: Women in Science 1830-2000," hosted by the Royal Society, and Carl Thompson's "Women's Scientific Travelling Before 1850," held at the Institute of Modern Languages Research. Both were concerned with the ways in which women have operated as gatekeepers to knowledge and how women scientists have brought different perspectives and new aspirations to bear on the fields in which they work. The papers presented at these conferences still owe much to foundational scholarship from the 1980s and 1990s that sought to restore the position of women in science writing: collections edited by Pnina G. Abir-Am and Dorinda Outram, Marina Benjamin, and Barbara T. Gates and Ann B. Shteir remain pivotal studies in understanding the contributions that women made to the physical and natural sciences. Annotated bibliographies of women in science that have appeared with increasing regularity over the past couple of decades are now proving particularly useful in bringing hitherto overlooked female figures in scientific research, authorship and knowledge dissemination, to public attention. Works such as Marilyn Ogilvie and Joy Harvey's Bibliographical Dictionary of Women in Science (2000) and Mary Brück's Women in Early British and Irish Astronomy: Stars and Satellites (2009) now serve as extremely valuable sources by which to gain a wider overview both synchronically and diachronically of women's involvement in a range of scientific fields. And Deborah Jaffé's intriguing 2003 collection of material on British women as scientific inventors - from Sarah Guppy's 1811 patent of a "New Mode of Constructing and Erecting Bridges and Railroads without Arches" which inspired 
Thomas Telford's suspension bridge designs to Emma Pike's more domestic 1890 patent for a "Bronchitis Kettle" - quite literally demonstrates the extent of women's inventiveness in the Regency and Victorian periods (Jaffe's Appendix 169ff).

More recent publications have either continued to group women's involvement around the particular field to which they contributed - botany in particular, but also entomology, marine biology, geology, astronomy or mathematics - or to concentrate on a biographical case study as a way of investigating close-up the networks in which one particular scientifically-minded woman operated. Sam George's Botany, Sexuality and Women's Writing, 1760-1830 (2007) has, for instance, been particularly instructive in demonstrating how productive the relationship between literary writing and botany was for women working in the eighteenth and nineteenth centuries, and how it could be used to initiate crucial debates around gender, sexuality and culture. Botanising women favoured a variety of different genres of writing that could, for example, be dialogic, epistolary or confessional in style, depending on the audience which they were aiming to target. Such narrative strategies potentially side-lined women as mere "popularisers" of knowledge, who posed the least threat to their male counterparts by relegating themselves to the sphere of children's science writing or elementary science books for adults. Nevertheless, they highlight the themes of sociability, transmission and exchange that influence the ways in which scientific knowledge is constructed, and which inform all of the articles in this special issue.

Biographical studies such as Lucy Lethbridge's Ada Lovelace: The Computer Wizard of Victorian England (2001) and, more recently, James Essinger's A Female Genius: How Ada Lovelace, Lord Byron's Daughter, Started the Computer Age (2013) have reflected on the impact that women could make on men's thinking. Ada Lovelace's 1843 translation from the French of an article on the "Analytical Engine" by an Italian engineer, Luigi Menabrea - to which Ada added extensive notes of her own - made an original but today largely overlooked contribution to computer science in its very infancy through its influence on Charles Babbage's work. While such "popular," "cross-over" biographies tend to highlight the exceptional nature of women's contribution to science and hype up their individual genius, more scholarly histories of science have generally emphasised the collaborative nature of both male and female endeavours in the field. James Secord's article on how science was a key part of conversational culture into the $1860 \mathrm{~s}$ - a decade described by Patricia Phillips as something of a cut-off point for women's engagement in science (The Scientific Lady 235) - suggests that the "polite" science of the first half of the nineteenth century still enabled a broad range of individuals to be involved in scientific knowledge-making in a more informal setting. Seeing women less as singular prodigies and more as figures embedded in different networks of scientific exchange has been more helpful of late in understanding how they developed their talents in settings which were not necessarily as controversial or spectacular as one might imagine. While Mary Somerville, for example, undoubtedly occupied a unique position in Victorian science as an integral part of the British scientific community, as Kathryn A. Neeley's study Mary Somerville: Science, Illumination, and the Female Mind (2001) shows, she achieved this status through carefully managing her gender identity and by producing highly readable, authoritative scientific literature that was both rhetorically compelling and aesthetically engaging. Suzanne Le-May Sheffield's Revealing New Worlds: Three Victorian Women Naturalists (2001) offers a comparative analysis of three women arguably of lesser scientific standing: Margaret Gatty, who specialised in the study of seaweeds and other marine life, the botanical 
artist and scientific traveller Marianne North, and Eleanor Anne Ormerod, now classed as an "economic entomologist" for her work on how to eradicate insects injurious to orchard crops. It offers us a valuable insight into how women negotiated the discontinuities and non-linearities of life as scientifically-interested women operating within the norms of Victorian femininity and domesticity that put them at a distinct disadvantage over their male counterparts. Most recently, Robyn Arianrhod's Seduced by Logic: Émilie du Châtelet, Mary Somerville, and the Newtonian Revolution (2012) has drawn attention to the role that women played as translatoreditors in the Victorian scientific community and highlighted what women contributed to science but also what it gave back to them.

The focus in this special issue is primarily on the nineteenth century as a period in which women could engage increasingly publicly with science. The five articles that make up this collection explore women's engagement with science writing in the nineteenth century from a variety of different angles. They present, in chronological order, a number of different ways of understanding the encounters between women who wrote science and the varied audiences whom they sought to reach with their work. Some of these audiences were decidedly "serious" and others more "popular." While the negative connotations of the term "popularisation" have been debated at length, Barbara T. Gates and Ann B. Shteir have argued for "popular science" to be seen as its own form of knowledge "shaped in relation to the needs of audiences beyond elite and learned culture" (4) and it is very much in this light that we explore how women were keen to promote the outward expansion of scientific knowledge in search of wider readerships. In what follows, we will therefore be discussing a range of different forms of textual engagement with science - the travelogue, the manual, the catalogue, the elementary instructional book, the translation - as we examine issues of authorial intent and narrative strategy. Given that the technology of book illustration - and the costs associated with it - changed radically over the course of the nineteenth century, we shall also be investigating how the relationship between text and image complicated or facilitated scientific knowledge construction for women writing, editing and translating scientific literature.

Focusing on the English rendering of Martin Heinrich Lichtenstein's Reisen im südlichen Afrika (1811) by the Norwich-born translator Anne Plumptre (published as Travels in Southern Africa), Alison E. Martin investigates how women could combine their knowledge of modern foreign languages - particularly German - and scientific expertise to good effect, thus adopting a pivotal position as facilitators in the onward transmission of scientific knowledge. The important role played by women in scientific translation is only gradually beginning to be recognised and researched (Martin, "The Voice of Nature"; "Translation, Scientific Travel Writing and Modernity"), because they tended to hide their involvement for reasons of modesty or because publishers considered translators' input too minor to name them on the titlepage. But Plumptre exploited the de-centred, marginal spaces that she could occupy as annotator of her own translation to criticise, correct or complement Lichtenstein's scientific assertions. She therefore harnessed the performative potential of translation to demonstrate her facility with scientific ideas, concepts and terminology, while casting herself as an adroit diplomatic negotiator of the complex politics of international scientific networks.

Mary Orr continues to explore the role of women as translator-editors in her discussion of Sarah Bowdich Lee's Taxidermy, which appeared anonymously in 1820. 
While the contribution that Bowdich makes to the practice of taxidermy is in itself ground-breaking, Orr argues, the intertextual quality of her work - part translation from the French of Louis Dufresne's 1816-19 "Taxidermie" article, part addition of her own weighty instructions for "Museums and Travellers" - is also highly revealing of the knowledge markets that she targeted with her work. Bowdich, like Plumptre, was present paratextually in Taxidermy in various ways, using what Orr deftly describes as the "footnote zone" as a space in which this extremely visible participant in the onward transmission of expert knowledge could emphasise her own active involvement. The hybridity of the text Bowdich constructed in Taxidermy stands as testimony to the fact that reconfiguring and enriching the practices of science and their documentation was not solely the preserve of men.

Carl Thompson's discussion of Maria Graham's editorial work on the Voyage of HMS Blonde (1826-27) focuses on what was probably one of the most complex texts commissioned by John Murray II, whose publishing house was one of the leaders in producing scientific travel writing. By exploring how Graham handled the natural historical data from the voyage, Thompson sheds new light on how Maria Graham grappled as an editor with the scientific papers collated from the Blonde voyage (1824-25) to Hawaii. While Graham was, of all the women on whom this collection of essays focuses, probably the one most publicly recognised for her contribution to professional science in her time, her editorial work on the Voyage of $H M S$ Blonde has also attracted the most criticism. Thompson refutes allegations that Graham was the cause of scientific deficiencies in the account and highlights instead the problematic nature of the source documents with which she was working. As with Plumptre and Bowdich, Graham adopted an active role in enhancing the account's scientific content, while also showing an awareness of the scientific and literary agendas to which travel writing still needed to adhere.

The fourth article, by Susan Pickford, analyses how participants excluded from formal knowledge exchange networks were nevertheless able to make use of the informal networks in which they operated to contribute to the construction of scientific knowledge. Focusing on Etheldred Benett's Catalogue of the Organic Remains of the County of Wiltshire (1831) as a print artefact, Pickford shows how its privately printed status appears to suggest complicity with a modesty topos. Yet this is tacitly denied by the patterns of distribution which Benett was herself relatively well able to control, given the limited print run of her work. Women like Benett have tended to be overshadowed by scholarship on the young men whose discoveries shaped early writing in the earth sciences. However, as Pickford demonstrates, Benett offers a particularly fascinating study of how the limited circulation of their work could enable women to escape censure and, through carefully depositing their work with key libraries, could disseminate their discoveries unostentatiously to highranking figures of the male scientific establishment.

Finally, Angela Byrne's article examines the construction of natural knowledge about Canada in Catherine Parr Traill's scientific works for children. Traill disseminated her experiences as a settler in Upper Canada from 1832 onwards through an impressive range of publications, including children's fiction, emigrants' guides and natural historical works. While she cast herself merely as a "gleaner" of knowledge and actively employed modesty topoi, Traill's success owed much, Byrne argues, to an awareness of the possibilities that changes in the publishing market were opening up to women. Her own international networks - which included "men of science" as much as interested laypeople - provided her with data, specimens and 
information that illustrate her pivotal position in knowledge production that transcended national and social boundaries. While Traill's desire to amuse and instruct gave her natural historical writing broad appeal, her religious beliefs also shaped her vision of Canadian natural history. Byrne's closing discussion of the illustrations in Traill's books is particularly instructive in revealing the tensions between the "domestic" and the "wild" that made these works fascinating books for Canadian, American and British children alike.

The articles in this special issue do not necessarily suggest that a linear development can be traced that charts women's increased involvement in the transmission of scientific knowledge through the nineteenth century. But the grouping of the three articles by Orr, Thompson and Pickford in the 1820s and 1830s suggests that these were particularly effective decades in women's establishment or consolidation of their position as disseminators of knowledge within scientific fields. The women whose work is explored in this collection do not appear to have been directly linked with each other in any way, and no textual cross-referencing suggests any recognition of each other's work. As such, they present rather isolated cases of British women's engagement with science - an image which further scholarship can only begin to refine. The variety of roles that women took on - as authors, editors, translators, illustrators and as preservers of scientific specimens - is testament to their own creativity in finding outlets for their intellectual curiosity and ambition, stimulated in the case of Bowdich, Graham and Traill, by travel to more exotic parts of the world. Each one of these case studies reveals, then, in different ways how Chenevix's assertion that women were "by nature, timid, retreating, little confident" (II: 319) was demonstrably untrue. 


\section{Notes}

Alison E. Martin would like to thank the Journal of Literature and Science for enabling her to edit this special issue, the anonymous readers for their helpful comments on each of the articles, and Carl Thompson for his swift and helpful feedback on this introduction. 


\section{Works Cited}

Chenevix, Richard. An Essay upon National Character: being an Inquiry into Some of the Principal Causes which Contribute to Form and Modify the Characters of the Nations in the State of Civilisation. 2 vols. London: Duncan, 1832.

Darnton, Robert. "'What is the history of books?' Revisited." Modern Intellectual History 4.3 (2007): 495-508.

Gates, Barbara T., and Ann B. Shteir. "Introduction: Charting the Tradition." Natural Eloquence: Women Reinscribe Science. Ed. Barbara T. Gates and Ann B. Shteir. Madison: U of Wisconsin P, 1997.

Jaffé, Deborah. Ingenious Women: From Tincture of Saffron to Flying Machines. Thrupp: Sutton Publishing, 2003.

Martin, Alison E. "The Voice of Nature: British Women Translating Botany in the Early Nineteenth Century." Women in Translation. Ed. Luise von Flotow. Ottawa: Ottawa UP, 2010. 11-35.

---. “These changes and accessions of knowledge': Translation, Scientific Travel Writing and Modernity - Alexander von Humboldt's Personal Narrative." Studies in Travel Writing 15 (2011): 39-51.

Phillips, Patricia. The Scientific Lady: A Social History of Women's Scientific Interests. New York: St. Martin's Press, 1990.

Schiebinger, Londa. "The History and Philosophy of Women in Science: A Review Essay." Signs: Journal of Women in Culture and Society 12 (1987): 305-32.

Secord, James A. "How Scientific Conversation Became Shop Talk." Transactions of the Royal Historical Society 17 (2007): 129-56.

---. "Science, Technology and Mathematics." The Cambridge History of the Book in Britain: Volume VI, 1830-1914. Ed. by David McKitterick. Cambridge: Cambridge UP, 2009. 443-74.

Sleigh, Charlotte. Literature and Science. Basingstoke: Palgrave Macmillan, 2011. 